\title{
Erratum to: An Endoscopic Strategy Combining Mega Stents and Over-The-Scope Clips for the Management of Post-Bariatric Surgery Leaks and Fistulas (with video)
}

\author{
Hany M. Shehab ${ }^{1} \cdot$ Sherif M. Hakky ${ }^{2} \cdot$ Khaled A. Gawdat $^{3}$
}

Published online: 5 November 2015

(C) Springer Science+Business Media New York 2015

Erratum to: OBES SURG

DOI 10.1007/s11695-015-1857-6

Figure 1 was displayed incorrectly in the original version of this article. It is now correct in the updated version of the article.

1 Gastrointestinal Endoscopy Unit, Gastroenterology Department, Kasr Alainy University Hospital, Cairo University, Cairo, Egypt

2 Bariatric Surgery Department, Kasr Alainy University Hospital, Cairo University, Cairo, Egypt

3 General Surgery Department, Ain Shams University Hospital, Ain Shams University, Cairo, Egypt 